\title{
LA NOCIÓN JURÍDICA DE FUNCIONARIO PÚBLICO. CONTRIBUCIÓN TEÓRICA A UN DEBATE PERENNE.
}

\author{
THE LEGAL NOTION OF A PUBLIC OFFICIAL. THEORETICAL CONTRIBUTION \\ TO A PERENNIAL DEBATE
}

Recebimento em 14/10/2020

Fernando Monzón Páez ${ }^{1}$

\section{RESUMEN}

El presente artículoofrece una propuesta en torno a la construcción teórica de la categoría funcionario público, a partir de un enfoque que permita su tecnificación para el Derecho Administrativo con una vocación de universalidad. Así, se presentan algunas notas sobre la cuestión de la diversidad terminológica, conciertas precisiones de alcance y de contenido y se valora la diversidad de planteamientos y perspectivas en cuanto a su definición jurídica como tipología esencial dentro de la dimensión subjetiva de la función pública. Finalmente, se propone que la categoría funcionario público debe delimitarse por un elemento objetivo -integrado por el ejercicio de función administrativa, la naturaleza estatutaria de la relación de servicio y la ordenación mediante un régimen de Derecho Administrativo-; un elemento subjetivo determinado por la presencia de la Administración Pública y la persona física que ostenta el status funcionarial- y un elemento formal -compuesto por los mecanismos jurídicos mediante los cuales puede concretarse el vínculo, sean unilaterales o consensuales.

Palabras claves: Derecho Administrativo. Función Pública. Funcionario Público.

\section{ABSTRACT}

This article offers a proposal around the theoretical construction of the public official category, based on an approach that allows its technification for Administrative Law with a vocation of universality. Thus, some notes on the issue of terminological diversity are presented, with certain details of scope and content and the diversity of approaches and perspectives regarding its legal definition as an essential typology within the subjective dimension of the public function is valued. Finally, it is proposed that the category of public official should be delimited by an objective element -integrated by the exercise of an administrative function, the statutory nature of the service relationship and the organization through a regime of Administrative Law-; a subjective element -determined by the presence of the Public Administration and the natural person who holds the public servant status- and a formal element -composed by the legal mechanisms through which the link can be specified, be they unilateral or consensual.

\footnotetext{
${ }^{1}$ Profesor de Derecho Administrativo de la Facultad de Derecho de la Universidad de La Habana. Doctor en Ciencia Jurídica (Universidad de La Habana, 2020), Máster en Derecho de la Economía (Facultad de Derecho de la Universidad de La Habana, 2017).
} 
Keywords: Administrative Law. Public Function.Public Official.

\section{A MODO DE PREÁMBULO}

El fenómeno de la ordenación de los medios personales al servicio del poder ha sido heterogéneo y con matices variopintos en su tracto evolutivo. Su complejidad se ha incrementado en la medida en que el Estado va creciendo, ampliando su ámbito de intervención social y, consecuentemente, el componentehumano como uno de los medios de los que se vale también prolifera, se tecnifica y actúa en las distintas esferas que van perfilándose en virtud de la individualización de las funciones estatales a partir, fundamentalmente, del proceso de profesionalización de las funciones públicas.Dentro de ese conglomerado de personas, que intervienen y hacen posible el funcionamiento administrativo público, la categoría esencial es el funcionario público, de vital importancia dentro del componente subjetivo del Estado, por identificarse habitualmente con las personas que tienen un nivel más elevado de deber y responsabilidad en el ejercicio de la función pública.

El cursar de la historia demuestra que desde la existencia misma del poder organizado hay agentes de ese poder y, aunque tal realidad tiene raíces muy remotas, es preciso advertir que los antecedentes e influjos más directos de la noción jurídica de funcionario público se localizan, fundamentalmente, en el proceso evolutivo de la Administración Pública y del Derecho Administrativo, como subsistema jurídico. Se trata, pues, de una categoría jurídica producto del Estado moderno con una concreción más exacta en el Estado constitucional que solo es coherente en el contexto de una diferenciación precisa de las funciones del Estado, con la presencia de un aparato administrativo jerarquizado y profesional.Por ello, fundamentalmente durante el siglo XIX, es que se van configurando las notas teóricas y prácticas que van diferenciando jurídicamente los diferentes tipos, a lo interno, de ese personal al servicio del Estado -con mayor concreción aquellos que sirven a la Administración Pública, como espacio más preciso de actuación.

Sin embargo, lejos de resultar una institución de perfiles definitorios precisos, ha sido una de las que ha padecido mayores avatares en lo teórico y aún, al cabo de más de dos siglos, las polémicas que la circundan no han sido zanjadas. En este sentido, si se intenta realizar un planteamiento general, puede decirse que las referidas dificultades se direccionan bajo la 
influencia de dos factores que han condicionado los debates hasta la actualidad: un factor teórico y un factor contextual.

El primero de ellos tiene varias vías de manifestación, entre ellas, las complejidades derivadas del componente gnoseológico que ha de desentrañarse como presupuesto para cualquier aproximación teórica a la categoría funcionario público y que involucra otras, igualmente polémicas, como la noción de lo público o de función pública. Las propias referencias semánticas que aparecen del vocablo funcionario público muestran una perspectiva polisémica en cuanto a su sentido y alcance, y la ausencia de una concepción teórica consensuada es una realidad que permanece e impide diferenciarlacomo categoría con autonomía conceptual; lo que dificulta la identificación certera de aquellos elementos que le son intrínsecos.

El factor contextual o histórico, por su parte, deviene condicionante de todas las concepciones que se han tenido de funcionario público, lo que se constata de la observancia de las propias peculiaridades que las corrientes doctrinales y jurisprudenciales han estampado al asunto, fundamentalmente en virtud de sus intentos definitorios como categoría jurídica, en diferentes escenarios espacio-temporales. Ello encuentra una parte importante de su explicación en el carácter nacional que la circunda, al estar estrechamente vinculado con la propia cultura política y jurídica de cada realidad estatal específica.

A lo anterior, debe adicionarse que el escenario más reciente ha colocado dificultades mayores en virtud de fenómenos como la mixtura de los modelos de ordenación de la burocracia pública o el denominado proceso de laboralización de la función pública.Ello, coloca mayor interés en la conservación del particularismo jurídico de la condición funcionarial.

Ante este panorama, el presente trabajo tiene como objetivo reflexionar sobre algunas de las problemáticas planteadas para realizar, en lo fundamental, una propuesta teórica de la categoría funcionario público, sustentada en una serie de elementos que permitan su tecnificación para el Derecho Administrativo con determinado grado de generalidad y aceptación.

\section{LA CUESTIÓN DE LA DIVERSIDAD TERMINOLÓGICA: PRECISIONES DE ALCANCE Y DE CONTENIDO}

El primer gran problema que ha de enfrentarse al abordar la temática global de la ordenación de los medios personales al servicio de la Administración Pública, es la diversidad de denominaciones que han aparecido en los últimos doscientos años en la legislación, la 
jurisprudencia y en la doctrina de diferentes latitudes, que se refieren a las tipologías de personas que integran las estructuras administrativas del Estado (agentes, oficiales, funcionarios, servidores, autoridades, directivos adjetivadas, mínimamente, de cuatro maneras distintas: públicos, estatales, gubernamentales, administrativos (as), empleados del Estado, empleados públicos, personal administrativo, personal del Estado, agente oficial, servidor oficial, empleados oficiales, dependientes del Estado, solo por mencionar algunos ejemplos).De tal modo, observar nada más el panorama del etiquetamiento que gravita en torno a los medios personales del Estado, incluso en un ámbito más concreto, al propio funcionario público, podría resultar desconcertante.

Este escenario variopinto determina una segunda vía de manifestación, referida al alcance, también muy dispar, que cada una de esas categorías puede llegar a tener. En este entendido, si bien es cierto que no existen tantos alcances como vocablos enunciados porque varios de ellos, aunque diferentes en su denominación, llegan exactamente el mismo alcance, puede presenciarse también el caso de otorgamiento de sentido distinto para un mismo apelativo, según el contexto nacional donde se emplee.

Consecuentemente, desde esa diversidad y complejidad, resulta muy difícil encarar cualquier análisis que pretenda una construcción más unitaria y sistémica. Por tanto, en la búsqueda de ese nivel de precisión, es necesario un ejercicio previo de descarte de un grupo de aquellas designaciones y alcances que, por una u otra razón, no son funcionales para la noción técnicojurídica de funcionario público que se propone.

De modo general, en cuanto a la propia denominación de la categoría han de prescindirse de todas aquellas que por mera filología no tengan vocación para indicar la esencia del fenómeno socio-político al que se refieren; esto es, el ejercicio de las funciones del Estado por las personas físicas, con el componente axiológico que ello debe tener en la actualidad: la naturaleza servicial del Estado y, concretamente, de la Administración Pública. Con este criterio, las alternativas se reducen automáticamente a los vocablos de 'funcionario' y 'servidor'. Otras de las denominaciones que han sido reflejadas tienen una prospección sobre realidades muy concretas, que no resultan propicias por reduccionistas.

En un segundo momento, el proceso de filtraje ha de direccionarse respecto del alcance que la expresión deba tener, según sea el uso que se le vaya a dar. En este caso, el espectro es más reducido, pero no menos importante, porque la adjetivación de los vocablos funcionario o servidor determina la primera condición de funcionalidad de la categoría, que es dotarla de un sentido y alcance lingüístico preciso. 
En este caso, igualmente hay que tomar como punto de base las cuestiones esenciales que demandan la selección del vocablo adecuado. Al respecto, debe considerarse, en primer orden, los dos alcances fundamentales que han de determinarse. El primero, con el objetivo de identificar la categoría idónea como referente genérico de todas las personas que de cualquier manera ejercen o participan del ejercicio de las funciones del Estado. Luego, también es necesario tener alocuciones aptas para designar los tipos o especies que se desgajan de ese género.

Esto es elemental porque para poder realizar las construcciones teóricas correspondientes a la categoría funcionario público es preciso establecer su conexión coherente dentro del esquema categorial que conforma el elemento personal que mueve la maquinaria estatal, dentro del cual se inserta el funcionario público como un componente particular. La premisa básicaversa sobre la carga axiológica de la que se quiere dotar a la expresión que se use. Consecuentemente, el vocablo idóneo para esto es 'servidor'que, debe adjetivarse con el apelativo 'público'ya que, en su sentido más global, aglutina al Estado todo en su despliegue funcional y estructural. Si el patrón de referencia, en correspondencia con la lógica seguida, es el Estado y sus funciones, pues habrá tantos servidores públicos como esferas funcionales tenga el Estado-paraidentificar espacios estructurales y de funcionamiento más concretos.

Solo queda, pues, en el orden terminológico, una última precisión respecto al uso de la expresión funcionario público para la que prefiero un sentido y alcance muy estricto, referido a un tipo especial de servidor administrativo.En el plano de lo ideal pudiera considerarse simplemente un alcance amplio de lo que indica la alocución 'funcionario público', porque conecta de manera inequívoca con el ejercicio de una funciónque ejerce una persona física y que es pública porque es del Estado; lo cual, desde una perspectiva etimológica, sería una alternativa adecuada. El argumento definitorio de su descarte como género lo fue, hace un momento, el valor axiológico dado al vocablo 'servidor', en cuyo caso, lo que seguiría, según la dinámica expresada, es subclasificar a los servidores administrativos en cuanta tipología se requiera (servidor administrativo profesional o no profesional, honorario, interino, colaborador, entre tantas otras alternativas según los criterios que se utilicen).

Sin embargo, la razón de quebrar esta lógica, en principio, es de tipo cultural y jurídico. La voz 'funcionario público', como figura de interés jurídico, es de base francesa, que se va a ir extendiendo a los países de su influencia en Europa y América, donde se fue asentando culturalmente. Ha sido en su virtud que se han generado los grandes debates teóricos en el ámbito administrativo y fuera de este. Es la que ha tenido una identidad y valor jurídico-técnico propios; connotación que sin dudas se vería resentida si se postula con un alcance amplio, 
equivalente al que se acababa de dar a 'servidor público'.De lo que se trata es de consolidar a la categoría funcionario públicodesde el punto de vista científico en pos de su funcionalidad jurídica, que hoy no termina de cuajar, pero manteniendo el uso de la expresión, originalmente concebida.

Por otra parte, como oda a la conservación de la figura del funcionario público, según lo argumentado, debe considerarse en este caso el sentido de lopúblico asociado a lo administrativo. Cuando se diga entonces que el 'funcionario'ejerce una 'función', y esta es 'pública', hay que apelar a la idea de función pública como función administrativa. En tanto, ha de descartarse cualquier otro apelativo que desvirtúe el alcance pretendido de la expresión.

\section{LA NOCIÓN DE FUNCIONARIO PÚBLICO: PLANTEAMIENTO Y PERSPECTIVAS DIVERSAS}

$\mathrm{Al}$ abordar la temática relativa a la función pública $\mathrm{y}$, concretamente, la noción jurídica de funcionario público, lo único común y de pacífica aceptación ecuménica es la inexistencia de alguna concepción que cuente con anuencia universal. Esta está siempre ligado a un Estado determinado y no puede considerarse fuera de aquel, de su historia, de su legislación y de la jurisprudencia de sus tribunales (RoYO-VILLANOVA, 1964). ${ }^{2}$

Esta realidad, además, es fácilmente verificable mediante el estudio de las diferentes definiciones que en el transcurso de la historia se han ofrecido de la figura funcionarial dentro y fuera del Derecho Administrativo. Las razones fundamentales se concentran en el propio aspecto lingüístico referido al uso común del término y las diferentes acepciones jurídicas y en el aludido factor contextual, que ha condicionado la inclusión o exclusión de elementos que varían el sentido y alcance del vocablo.

Los autores se han enfocado en distinguir la categoría funcionarial a partir de criterios disímiles, que conducen a formulaciones conceptuales de magnitudes dispares, construyéndola sobre la base de elementos objetivos, subjetivos, materiales o formales, indistintamente; sin dejar de mencionar la articulación de definiciones sectoriales que se han realizado, en lo fundamental, desde el ámbito penal, fiscal o tributario y hasta en el de la lucha contra la corrupción, esfera de más reciente preocupación. Sin embargo, el fenómeno puede enfocarse, de modo general, desde

${ }^{2}$ Sobre esta idea puede verse también NEZARD (1922, p. 117),PlanteY (1971, p. 21), TREVIJANO-Fos (1970, p. 402). 
dos perspectivas elementales: las nociones a lo interno o externo ${ }^{3}$ del Derecho Administrativo y las concepciones, dentro de este, con alcance más amplio o más estrecho. Cada una de ellas contextualizada por las circunstancias de tiempo y lugar, en lo político, teórico y jurisprudencial que las fueron condicionado. Veamos.

\section{A) LA NOCIÓN AMPLIA DE FUNCIONARIO PÚBLICO PARA EL DERECHO ADMINISTRATIVO}

Dentro del contexto evolutivo asimétrico de la concepción jurídica de funcionario público, una identificación primaria es la expresión de una noción amplia, que no necesariamente ha sido homogénea en todos los lugares y momentos. En tal sentido, una manifestación primigenia se conecta con el punto de partida histórico de la categoría en estudio (finales del siglo XVIII y siglo XIX francés) y que sirve de escenario a la más amplia concepción que se ha tenido de funcionario público como categoría de interés político-jurídico. En el campo lexicográfico, es ilustrativa a este respecto, como pone de manifiesto KAFTANI (1998, p. 67)la definición ofrecida por el Dictionnaire de la Constitution et du Gouvernementfrançaisde 1795. En una locuaz delimitación conceptual de funcionario público, lo cataloga como "título de quien sea elegido por el pueblo o designado por el rey para realizar una o más funciones del gobierno y que reciba sueldo del Estado [...], en una palabra, todo hombre sostenido por la nación, por el lugar que ocupa y la atención que él da a la administración temporal o espiritual del reino es un funcionario público". 4

Las reformas administrativas implementadas en la primera mitad del siglo XIX europeo se encaminaron a la consecución de un diseño administrativo sólido sobre el fundamento de la soberanía de la Nación, en el sentido revolucionario y la influencia filosófica del pensamiento rousseauniano del contrato social en Francia(RoUSSEAU, 1836), y en Alemania, sobre los principios de la teoría del Herrschaft; a partir de los cuales se estima que el Estado posee el poder de dominación de manera absoluta, con un poder de coerción que es inalterable(JELLINEK, 1914).

Consiguientemente, esto tendrá un impacto en la modulación de la idea de funcionario público y comienza a ser relevante el elemento de autoridad, con manifestaciones más contundentes en el ámbito francés, germano y, en menor medida, el español; ya sea asociado a la idea misma del

\footnotetext{
${ }^{3}$ Las que se concretan en lo externo, generalmente se inscriben como posturas amplias, pero su centro de gravitación fundamental no es la función administrativa y por tanto, merecen un espacio de análisis aparte por sustentarse sobre cánones y proyecciones diferentes. Asunto al que no podemos, por razones de espacio, dedicar atención aquí.

${ }^{4}$ En su obra, la autora devela el primer uso del sintagma funcionario públicoen un sentido moderno, según se tiene referencia. Lo atribuye a TURGOT en el año 1770, contenido en una instrucción relativa a la Mendicité.
} 
poder delegado por el Estado a quienes están llamados a ejercer sus funciones o asimilada a la perspectiva ejecutiva o de gobierno, en su sentido más amplio. Lo anterior encuentra una explicación en la influencia teórica de la doctrina de la doble personalidad del Estado, que primó durante el siglo XIX e hizo sentir también sus efectos en la concepción de funcionario público. ${ }^{5}$ Así, por ejemplo, en Francia es notable la incorporación del rasgo de autoridad en las definiciones decorte ampliocon fuerte arraigo durante el siglo XIX y principios del XX, aproximadamente. ${ }^{6}$

En Alemania, por su parte, la idea de autoridad como poderse manifiesta como fundamento de uno de los elementos claves que históricamente han sustentado la noción germánica de funcionario público: la relación especialísima entre el Estado y el funcionario. Con poderosas raíces en el vínculo de fidelidad de raigambre feudal y la supremacía del poder público sobre sus agentes, la relación de servicio marca un centro de atención cardinal. ${ }^{7}$

En cuanto a España, en elpropio periodo decimonónico, es menos común encontrar definiciones precisas de funcionario público; sin embargo, en cierto modo, se hace notar la influencia francesa y germánica al respecto de lo antes expresado. En OLIVAN, por ejemplo, si bien no se halla un concepto propiamente de funcionario y se evidencia un uso indistinto de los vocablos funcionario, agente administrativo o empleado, es visible la idea de la particular vinculación fiel de los funcionarios con el Estado, basado en su poder supremo (OLIVAN, 1843). ${ }^{8}$

Para la doctrina italiana, el vocablo funzionariapareceen un sentido más genérico, por el peculiar uso histórico de la categoría impiagatopara referirse propiamente al funcionario profesional. Es perceptible también, en algunos casos, la asimilación de expresiones funcionario ofunzionari con otras comoimpiagatou ufficiali, ${ }^{9}$ oagenti(MANNA, 1860);lo que dificulta un poco la homogenización del análisis.

A partir del siglo $\mathrm{XX}$, las nociones de funcionario público fueron modulándose con matices y perspectivas variables. La tendencia será a reducir su alcance sobre la base de la incorporación de

\footnotetext{
${ }^{5}$ La primacía de esta teoría, incluso tuvo un mayor impacto en la noción de funcionario público a partir de que BERTHÉLEMY la toma como fundamento para la distinción que realiza entre funcionarios de autoridad y funcionarios de gestión. Criterio que es adherido y mantenido durante un tiempo por parte de la doctrina. (BERTHÉLEMY, 1913). Esta concepción pretendió servir como criterio de distinción entre el funcionario -en sentido estricto- y los empleados o personal técnico o auxiliar de la Administración Pública. LAFFERRIERE (1896) ;NÉZARD (1901).

${ }^{6}$ Véase, por ejemplo, MACAREL (1844), VIVIEN (1845), BATBIE (1885), NÉZARD (1922).

${ }^{7}$ En el caso alemán, el tratamiento de la noción de funcionario público se manifiesta de manera más uniforme sobre la base de estos fundamentos y hasta la actualidad se ha mantenido, en sentido general, la consideración bifurcada de la concepción funcionarial en un sentido amplio y otro más restricto, reservando esta última para los que ejercen función pública con carácter profesional.LABAND (1901), MAYER (1982).

${ }^{8}$ En sentido general, puede apreciarse cierta diversidad en el uso de diferente terminología como, por ejemplo, "autoridades administrativas", equiparable por su tratamiento a una noción amplia de funcionario (GÓMEZ DE LA SERNA, 1843), o "agente" o "empleados del Estado" (SARALEGUI Y MEDINA, 1865), o la concepción general de que la idea de funcionario público abarca a cuantos ejercen una función del Estado. (POSADA, 1897).

${ }^{9}$ BOCCARDO (1863); SCOLARI (1866); ORLANDO (1889).
} 
elementos de disímil naturaleza. No obstante, tomando como patrón de amplitud o estrechez la conexión con el Estado o la Administración Pública, las concepciones amplias han continuado presentes hasta los tiempos actuales. Bastaría una rápida mirada en perspectiva teórica-evolutiva para reflejar este planteamiento. ${ }^{10}$

Ahora bien, la conexión con el ámbito funcional íntegro del Estado pudo tener sentido en el contexto originario de la categoría, bajo el ropaje de la filosofía liberal que, por principio, presenta una dinámica pública abstencionista donde, además, las funciones de gobierno, de justicia y de administración se funden en el concebido como poder ejecutivo. Sin embargo, un alcance de este tipo es solo operativo en realidades políticas donde el sector público tenga dimensiones estrechas o, en sentido general, la gestión pública esté en manos privadas, sea mediante mecanismos privatizadores o a través de modos administrativos de gestión indirecta o en colaboración público-privada. Sin embargo, en un escenario estatal más diverso, heterogéneo y complejo, no es funcional una perspectiva de esta índole.

A los efectos de tecnificación que aquí se persiguen,de lo que se trata, en gran medida, es de singularizar, al amparo de la categoría funcionario público, un grupo muy estrecho de servidores administrativos que, por su relevancia técnico-profesional y su vínculo especial con la Administración Pública, requieren una secularización de su régimen jurídico. Esta pretensión no es alcanzable si se engloba en ese particularismo a toda persona que trabaje para el Estado o que ejerza o participe del ejercicio de funciones públicas, en su connotación más amplia.

\section{B) LA NOCIÓN RESTRICTIVA DE FUNCIONARIO PÚBLICO PARA EL DERECHO ADMINISTRATIVO}

Siguiendo un criterio más estricto, existen concepciones que parten de identificar al funcionario público con la estructura y el funcionamiento de la Administración Pública concretamente; en cuyo caso, el vínculo estructural se establece con la organización administrativa y no con el Estado genéricamente. Estas posturas han sido consecuencia de las coyunturas sociopolíticas que

\footnotetext{
${ }^{10}$ Es apreciable desde la propia concepción de DUGUIT, en el contexto de la escuela francesa del servicio público (DUGUIT, 1928) hasta nociones más contemporáneas de varias latitudes, incluyendo la realidad latinoamericana: GIRIODI (1900); ROMANO (1906); ZANOBINI (1949); D'AlESSIO (1949); ViTTA (1954); SANDULLI (1989); ROYOVillanova (1948); GUAitA MARTORELl (1960); DieZ-QuiJADA (1962); BIELSA (1938); SAYAGUÉS LASO (1866); NúÑEZ BORJAS (1971); RONDÓN DE SANSO (1974); FERNÁNDEZ VÁZQUEZ (1998); FRAGA (2000).
} 
fueron determinando un cambio en el rol del Estado y de la Administración Pública, fundamentalmente desde los primeros años del siglo XX.

Entre los principales factores que al efecto influyeron se encuentra la amplitud de la esfera funcional del Estado y de la Administración Pública, en la medida en que fue exterminándose la concepción liberal, y el aumento considerable que naturalmente experimentó el personal técnico y auxiliar al servicio del Estado. En el plano jurídico destaca la evolución conceptual de la Administración Pública, que se perfila en sus aspectos orgánico y material; su diferenciación precisa y definitiva del resto de las funciones del Estado como ámbito funcional concreto e identificable con autonomía, encargado de la gestión del interés público; el desarrollo del Derecho del Trabajo y del Derecho Constitucional, que trajo aparejado el reconocimiento de derechos fundamentales a los funcionarios y su acercamiento al régimen jurídico laboral; entre otros.

Muchos de los elementos mencionados favorecieron, igualmente, el proceso que va conectando el sentido de lo público con lo administrativo y, como consecuencia, se coadyuva también a la sinonimia de función pública con función administrativa. Naturalmente, estas circunstancias irán recolocando los debates en cuanto la especialidad jurídica del régimen funcionarial. En tal sentido, se irá haciendo necesaria una delimitación más específica de ese creciente conglomerado de personal al servicio del Estado, cuya cuantía y esferas de desenvolvimiento, además, serán considerablemente mayores que en el resto de sus ámbitos funcionales, incrementándose, asimismo, la importancia política, técnica, práctica y jurídica de los agentes administrativos; ya no solo para establecer diferencias con el sector privado, sino también para concretar particularidades entre los que propiamente están vinculados al ejercicio de la función administrativa.

En este contexto, no solo se evidencia cierta concreción en las definiciones de funcionario público por la incorporación de algunos elementos ya apreciables en las concepciones expuestas como amplias; sino también se percibe una recolocación de la noción hacia los predios específicos de la Administración Pública, sea desde una perspectiva estructural identificando al funcionario público vinculado directamente con la organización administrativa o desde una óptica funcional considerando que este, materialmente, ejerce o participa del ejercicio de función pública o, más precisamente, de función administrativa.

HAURIOU (1927,p. 589),por ejemplo, entendía como funcionario a todo aquel que "en virtud de nombramiento por autoridad pública, pertenece al cuadro de los empleados permanentes de una 
Administración Pública". ${ }^{11}$ Rolland (1947, p. 71), en tanto, distingue al funcionario público a partir de la actividad material y por elementos objetivos y formales como la investidura por autoridad competente, ocupación de un empleo en cuadros organizados de un servicio público y la permanencia o cuasi-permanencia del empleo ocupado. ${ }^{12}$

Otros autores, aunque con meridiana claridad, sitúan al funcionario público en los contornos administrativos, refieren acercamientos conceptuales de perfiles más generales que denotan cierta ambigüedad. Así, GASCÓN Y MARín (1941, p. 285) planteaba que "la función exige al funcionario, siendo necesario que la Administración Pública actúe con personas físicas que le presten sus servicios y ejerzan sus funciones". 13

Por su parte, Royo-Villanova (1964, p. 9),a través de un prisma formal, también restricto, refiere que funcionario público es "toda persona que ocupe un puesto público en virtud de una adscripción legal hecha por el nombramiento o elección”. En cambio, desde una perspectiva funcional, PÉREZ BotiJA(1952, p. 128)establece una relación directa entre el funcionario público, el tipo de servicio que presta y la entidad desde donde la realiza. EnTREnA Cuesta(1957, p. 271), con óptica semejante, sustenta su criterio sobre la legalidad del nombramiento; permanencia en los servicios inamovilidad y pertenencia a la plantilla del cuerpo. ${ }^{14}$

En el entorno latinoamericano, la diversidad en el uso de vocablos diferentes para referirse al fenómeno funcionarial es incluso mucho más notable; lo que se debe, en parte, a que resultan más perceptibles los efectos de la mixtura entre los sistemas de ordenación de la función pública y las influencias de tradiciones jurídicas diferentes. En tal sentido, al ser mayormente utilizadas las expresiones servicio civil o empleo público en lugar de función pública, es también más frecuente el uso de los términos servidor público ${ }^{15}$ y empleado público, ${ }^{16}$ con acepción extensa. Pueden hallarse concepciones de índole restrictiva, como por ejemplo, la ofrecida por MARIENHOFF (1965, p. 14) que considera funcionario público a toda persona que "con alguna de

\footnotetext{
${ }^{11}$ De esta manera, la existencia y pertenencia a los cuadros, así como el requisito de permanencia, excluye del concepto al personal auxiliar y todo asalariado que no esté incluido en el cuadro; así como los casos de actividades concedidas.

${ }^{12}$ En esta misma línea de pensamiento: BONNARD (1943); JÉZE (1925-1930). Los tres autores anteriores, representantes de la escuela francesa del servicio público, se distancian de la concepción duguiniana al circunscribir la noción de servicio público al ámbito administrativo.

${ }^{13}$ Más recientemente, con un enfoque análogo, puede verse: PALOMAROLMEDA (1997).

${ }^{14}$ Esta concepción, muy específica, parece excluir tipologías como el funcionario honorario o situaciones como la eventualidad y la prestación de servicio con carácter interino.

${ }^{15}$ Véase, por ejemplo: PAREJA (1939); RodRíGuez R. (2017); MARTínEzBravo (2010); CAVAlCANTE (2010); LÓPEZ OLIVA (2013).

16 Véase, por ejemplo: SAYAguÉS LASO (1953); Cretella (1967); VidAL Perdomo (2008); CABRAL y SCHREGINGER (2009); YOUNES (2016).
} 
las modalidades establecidas en ley, realice funciones o contribuya a que se realicen funciones esenciales y específicas de la Administración Pública". ${ }^{17}$

Como se aprecia, las concepciones estrictas que se han construido son parte de un proceso inconcluso de tecnificación de la figura en estudio, durante el cual va dotándosele de elementos disímiles para distinguir propiamente al funcionario público dentro del conglomerado de agentes del Estado y de las especies que conforman subjetivamente la función pública. Consecuentemente, a los fines de deslindar, defender y conservar el particularismo jurídico de aquella y, como parte de él, dotar de perfiles técnicos más precisos a la categoría funcionario público,solo resulta viable apostar por una perspectiva estricta. Así. podrán establecerse parámetros más específicos para una construcción teórica que permita a la figura en cuestión desplegar toda su funcionalidad jurídica; para, de ese modo, coadyuvar al diseño de su régimen legal eficaz.

El punto de base es tener conciencia de que apelar a soluciones universales llevaría a quien lo intente a un callejón sin salida. Empero, tener como variable el factor contextual no es óbice para reconducir los debates sobre cimientos técnicos que permitan dotar a la categoría en estudio de una identidad jurídica administrativa propia. El escenario político-jurídico puede determinar su alcance más o menos estrucho, en función de los elementos que se consideren en un ordenamiento dado. Sin embargo, el sentido de la figura, como institución jurídica, ha de conectarse de modo inequívoco con su identificación dentro del catálogo de agentes administrativos; razón por la cual se defiende un enfoque estricto.

De tal modo, es naturalmente importante el análisis de los diferentes elementos que en distinta época y lugar han sido considerados para integrar teóricamente la noción de funcionario público. La utilidad de ello está en la recapitulación de los aspectos fundamentales circundantes a esos acercamientos conceptuales; pues, desde la mirada actual, no son elementos que puedan tenerse como aislados o independientes ni descartables per se, sino que son una acumulación de factores que han dado como resultado un fenómeno jurídico inacabado. Cada uno en sí mismo denota una construcción teórica con sus propias peculiaridades y todos, en lo individual y lo común, deben ser tratados desde una lógica evolutiva para comprender el valor que cada cual puede tener al tiempo de integrar los perfiles definitorios de la categoría funcionarial. Hagamos, pues, algunas valoraciones breves.

\footnotetext{
${ }^{17}$ Aunque analiza también una noción amplia de funcionario público -como toda persona que realice o contribuya a que se lleven a cabo funciones esenciales y específicas, es decir, fines públicos propios-. La diferencia entre estos puntos de vista radica justamente en el elemento formalista -en este caso la estipulación legal. A partir de esta consideración establece como elementos la profesionalidad del funcionario, la pertenencia a un cuerpo y la incorporación a un órgano administrativo.
} 
El componente históricamente más común y prácticamente invariable que puede aludirse es el ejercicio de función pública, alternado posteriormente con la participación en un servicio público. La conexión con la realización de una función o cometido del Estado ha sido la base fundamental para la necesidad, importancia y consideración especial de la ordenación de los medios personales a su servicio. Sin embargo, función pública y servicio público son conceptos jurídicos que cargan con una cuota importante de indeterminación. Consecuentemente, se ve disminuida su vocación como variables definitorias o, al menos, requerirían siempre de precisiones terminológicas previas.

Por su parte, centrar la atención en la relación estructural con el Estado, en general, o la Administración Pública, en particular, sin mayores puntualizaciones, tampoco resulta coherente con la existencia de personal que, como es sabido, puede ostentar la categoría funcionarial fuera de las estructuras administrativas, quedarían excluidos sectores donde se realiza actividad administrativa de modo secundario u otros ámbitos de funcionamiento estatal y aparatos públicos no precisamente administrativos, fundamentalmente, en esquemas descentralizados.

Dar valor preponderante a los elementos que, en definitiva, constituyen parte del contenido del régimen jurídico del funcionario público, igualmente torna vaga e inflexible cualquier definición que se proponga desde esa perspectiva. La estabilidad o permanencia en el puesto, ${ }^{18}$ por ejemplo, son presupuestos que suelen esgrimirse con mucha fuerza. No obstante, la dinámica de la función pública ha demostrado en la práctica que estos aspectos son circunstanciales y pueden o no estar presentes como intrínsecos a la categoría funcionarial, según el diseño que se adopte.

Por otra parte, al optar por un criterio de distinción de índole material, a partir de las actividades o tareas que se realizan, fundamentalmente tomando como eje la toma de decisiones, se pierde de vista que tal prerrogativa tampoco es inherente a la condición de funcionario público. No todos ellos tienen por imperativo entre su ámbito competencial la potestad decisoria ni, por tenerla, se excluyen de sus tareas acciones de ejecución. Razonamiento similar, en cuanto restrictivo, puede realizarse de los intentos definitorios sustentados en aspectos formales como el nombramiento. En tal caso quedarían excluidos, por ejemplo, los supuestos donde la relación funcionarial tiene una naturaleza contractual.

\section{EL FUNCIONARIO PÚBLICO COMO CATEGORÍA ESENCIAL DENTRO DE LA DIMENSIÓN SUBJETIVA DE LA FUNCIÓN PÚBLICA. ELEMENTOS QUE DEBEN SUSTENTAR SU NOCIÓN JURÍDICA}

\footnotetext{
${ }^{18}$ Con menos frecuencia el sueldo a cargo de los haberes públicos (ORLANDO, 1889) (ENTRENA CUESTA, 1957), con fuertes cuestionamientos en la actualidad bajo el entendido de la profesionalización de las funciones públicas y la consideración del funcionario público también como un empleado cuya remuneración puede tener fuentes diversas.
} 
Como premisa del análisis es importante el cuidado debido para la selección de los elementos que han de proponerse como esenciales. En este sentido, el resultado deseado es lograr que la confluencia de los que en tal condición se estimen, sea únicamente verificable en el considerado como funcionario público. La integración de sus contenidos, el sistema de relaciones que entre ellos se establezca y su sentido y alcance, aunque pueden variar, concretarán los particularismos de cada ordenamiento a partir de su concreción legislativa. Con independencia del modelo que se adopte, si en un ejercicio de confrontación se verifica que en la persona del servidor público de que se trate confluyen simultáneamente los elementos que se proponen, no habrá mayores inconvenientes para su identificación gnoseológica como funcionario público en sentido técnicojurídico estricto.

\section{A) EL ELEMENTO OBJETIVO}

Es claro que muchos de los elementos que se han esgrimido históricamente y que clasifican como objetivos, todavía constituyen sostenes importantes para determinar la condición funcionarial, por lo que no pueden ser descartados en un sentido absoluto, aunque la validación de algunos requería ciertas modulaciones desde una perspectiva técnica-metodológica para ser capaces de satisfacer las pretensiones de flexibilidad y adaptabilidad necesarias.

De modo general, la casi totalidad de aquellos elementos versaban sobre tres aspectos esenciales: la función que materialmente le es propia al funcionario, el vínculo con la Administración Pública y el régimen jurídico al que dicha relación está sometido. Con relación al primero de esos aspectos, dado el carácter técnico-jurídico con el que prefiero identificar a la categoría función pública,estimo de mayor precisión el sintagma función administrativa, cuyo significado, en el orden teórico-práctico es unívoco de manera más universal. En un sentido material, es esta la que el funcionario público ejerce propiamente y deviene, por tanto, un concepto capaz de abarcar todo su ámbito de intervención.

Por otro lado, respecto de los elementos que pretenden exaltar la especialidad del vínculo con la Administración Pública, es preciso partir de la cuestión esencial que determina ese particularismo que es su propia naturaleza. En este caso, su carácter estatutario, legal o reglamentario es pieza clave.

Asimismo, es capital la consideración de un régimen iusadministrativo para ser coherentes con la teleología propia de la Administración Pública, del Derecho Administrativo, de la función pública y del Derecho que la ordena. Por lo tanto, además, todos aquellos asuntos que se 
instrumentan en virtud de esa ordenación especial, deben considerarse incluidos dentro del régimen legal del funcionario público como parte de su contenido, atendiendo a las realidades concretas de cada Estado.

\section{A.1) El ejercicio de función administrativa}

El funcionario público, según los criterios defendidos, es una clase de servidor administrativo; por lo tanto, es de inmediata conclusión que, desde el punto de vista material, la función que ejerce es la función administrativa. En ella se localiza su ámbito de actuación y permite, además, identificarla en cualquier área del espacio público, sea en el seno de la organización administrativa, sea en entes descentralizados, en el ámbito de las funciones legislativa y judicial, etcétera. No existen mayores inconvenientes en afirmar entonces que el ejercicio de función administrativa es punto de partida y se erige como el primero del catálogo de elementos a tener en cuenta para perfilar conceptualmente al funcionario público. Sin embargo, no es ni puede estimarse suficiente para tal propósito, pues se trata de un elemento que le es común a todo servidor administrativo. ${ }^{19}$

\section{A.2) La naturaleza de la relación entre la administración y el funcionario público}

Tomando en cuenta la insuficiencia del ejercicio de función administrativa, a los fines de una delimitación precisa de lo que ha de considerarse funcionario público, es necesario determinar un segundo elemento como parte del componente objetivo propuesto. En este caso, se trata del vínculo jurídico que une al funcionario público con la Administración Pública y que define la relación jurídica funcionarial. La naturaleza de ese nexo es determinante para establecer las distinciones con el resto de las modalidades de servidores administrativos.

Es usual al abordar este tema encontrar también diversidad de nomenclaturas para referirse al mismo fenómeno. Algunos autores aluden a la naturaleza jurídica del vínculo que une al funcionario con el $\operatorname{Estado}^{20} \mathrm{o}$ a la naturaleza de la relación entre el ente público y sus funcionarios(ALESSI, 1970) o la denominan relación funcional(RUIZYGóMEZ, 1935) o relación de servicio $^{21}$.Otros prefieren hablar de la teoría jurídica(NEZARD, 1901) o naturaleza jurídicade la

\footnotetext{
${ }^{19}$ Es necesario tener en cuenta en este punto que no resulta trascendente la naturaleza pública o privada del ente o persona que realice la actividad, sino más bien la atribución de la función específica y la presencia de un presupuesto teleológico que determina su finalidad, enfocada a la satisfacción del interés colectivo como parte de los fines del Estado, cuya mano ejecutora es la Administración Pública.

${ }^{20}$ KAMMERER (1898); WALINE (1963); GASCÓN Y MARÍN (1941).

${ }^{21}$ GARCÍA-TREVIJANOFOS (1970); BATTINI (2003).
} 
función pública. ${ }^{22}$ Asimismo, hay algunos que estudian el asunto como naturaleza jurídica del empleo público o relación jurídica entre empleados y el Estado. ${ }^{23}$

Esta variedad referencial genera el principal inconveniente de no poder deslindar con exactitud los posibles vínculos jurídicos que pueden suscitarse entre el Estado, en general, y el funcionario público. Todos esos nexosson especiales, pero con características y efectos jurídicos diferentes. En tal sentido, es visible la presencia de tres tipos de relaciones que, de una forma u otra, son objeto del análisis de esta temática: la relación de servicio, la relación orgánica y la relación de empleo.

Tener claridad, en lo fundamental, de la configuración jurídica de la relación de serviciola más significativa para el status funcionarialy sus diferencias con las otras dos mencionadas constituye la base para las distinciones que se realizan, tanto en el momento de establecer la tipología básica del personal al servicio del Estado - para concretar la diferenciación entre los servidores administrativos-, como para sustentar las consideraciones que han de sostenerse respecto del carácter estatutario de la relación de servicio. Cada uno de estos vínculos tiene entidad y contenidos propios y, aunque puedan coincidir en el momento de su concreción, sus efectos jurídicos son igualmente diferentes.

Naturalmente no me es permitido extenderme sobre este tema que requiere, sin dudas, un análisis de mayor profundidad. Solo dejaré planteada la cuestión, a partir de algunas precisiones ineludibles a efectos de la postura presentada en este trabajo. En cuanto a lo que ahora más interesa, debe partirse de una idea precisa. La relación de servicioque une al funcionario público con la Administración Pública es, en primer lugar, objeto natural del Derecho Administrativo. A ella importa, no solo el vínculo en sí mismo y la prestación que se realiza a propósito de ella, sino también la virtud cívica y el compromiso ético con la función. ${ }^{24}$

$\mathrm{Al}$ asumir su naturaleza legal o reglamentaria, le es exclusiva al funcionario públicode entre el resto de los servidores administrativos y de ella dimana la condición funcionarial. Su contenido es general y prevé asuntos que son ajenos a cualquier otra disciplina: los derechos y deberes que se adquieren por la condición de funcionario público -no por el status laboral-, los principios que rigen la organización y funcionamiento del sistema de función pública, el régimen de responsabilidad de los funcionarios -fundamentalmente disciplinaria-, los procedimientos y mecanismos de acceso al ejercicio de la función administrativa, las limitaciones a la intervención de otras disciplinas, por ejemplo. La relación de servicio es la primera que se verifica (provee status) y, por tanto, es presupuesto de existencia de la relación de empleo, que determina destino.

\footnotetext{
${ }^{22}$ BERTHÉLEMY (1913); FraGA (2000); BIELSA (1966).

${ }^{23}$ OrLando (1889); Villegas (1951); PetrozZiello (1900); BALdini (1942).

${ }^{24}$ WELTER (1929); FRANCO (1993); RODRÍGUEZARANA (2013).
} 
Por su parte, la denominada relación orgánica, al igual que la relación de empleo, supone la incorporación del funcionario público a la estructura administrativa; aspecto que no es necesario para que se verifique la relación de servicio, pues su principal efecto jurídico es dotar al funcionario público de tal condición. Sin embargo, la relación orgánica introduce al funcionario en la organización administrativa ya no como mero empleado, sino también como elemento subjetivo (titular) del órgano administrativo, en tanto centro de imputación de voluntad. Consecuentemente, el principal efecto jurídico que este lazo tiene es que coloca al titular en el órgano para actuar sus competencias. ${ }^{25}$ La relación orgánica, al igual que la de empleo, implica destino, pero se refiere a un nivel muy específico al tratarse de un destino cualificado.

Por lo tanto, es claro que todo funcionario público entabla una relación de servicio con la Administración Pública, que puede derivar en un vínculo de empleo cuando sea asignado a un puesto de trabajo concreto $\mathrm{y}$, a la vez, puede devenir en un nexo orgánico si dicha asignación se realiza como titular de un órgano administrativo. Sin embargo, en cualquier caso ese status funcionarial provisto por la relación de servicio, subsiste con independencia de la materialización de alguno de los restantes nexos.

A.2.1) La naturaleza estatutaria de la relación de servicio

La naturaleza jurídica de la relación que une al funcionario público con la Administración Pública ha sido objeto de atención por parte de la doctrina y, en consecuencia, se han esgrimido diferentes concepciones para explicarla. Siguiendo la sistematización de RUIZ Y GóMEZ(1935, p. 69) de vieja data, pero aún válida, apoyado en el propio tracto evolutivo del Derecho Público, es posible afirmar que las teorías que han tratado de explicar la naturaleza jurídica de la relación funcionarial pueden catalogarse en tres grupos: teorías de Derecho Privado, teorías transitorias y teorías de Drecho Público. ${ }^{26}$

Sin embargo, en palabras deRoyo Villanova(1964, p. 19),“todo el mundo está conforme en que la relación de función pública es una relación jurídico-pública”. Existe, pues, consenso de que la relación de servicio engendra un vínculo jurídico en el que uno de los sujetos es la Administración Pública, personificada en un ente público, y cuya finalidad es el ejercicio de función administrativa, en el contexto de la satisfacción de una necesidad colectiva.

\footnotetext{
${ }^{25}$ En esta línea teórica puede verse: JELLINEK (1912); ALESSI (1970); GIANNINI (1991); CASSESE (1994); ENTRENA Cuesta (1957); Gallego Anarbitarte (2000); MARIEnhoff (1965); GArCía-Trevijanofos (1970); Barra (2003).

${ }^{26}$ Sobre las diferentes teorías que han explicado la naturaleza del vínculo del funcionario público con el Estado, puede consultarse entre muchos otros: KAMMERER (1898); NEZARD (1901); JORDANA DE POZAS (1924); CRETELLA (1967); SAYAGUES Laso (1953); VIDAL (2005).
} 
Consecuentemente, sus elementos, desde su fundamentación teórica hasta la articulación de su régimen jurídico, escapan al Derecho Privado.

En el orden de las ideas que se defienden en este artículo, podemos entonces referirnos directamente a la concepción legal o reglamentaria que es la que engrana coherentemente con la construcción teórica que se sostiene en torno a la noción de función pública, en general. Los fundamentos teóricos de esta postura la compatibilizan con los fines de la Administración Pública, como gestora del interés colectivo, y garantiza las prerrogativas de carácter unilateral que debe ostentar frente al funcionario público. Esta tesis vence sobre la postura contractual en el contexto de los fundamentos del Estado de Derecho y el principio de legalidad;en correspondencia con lo cual se entiende que el ejercicio legal del poder se efectúa en atención a un orden impersonal en el marco del cual no se genera obediencia a la persona que lo detenta en sí misma, sino al ordenamiento que establece los límites de la competencia objetiva de la función pública. $^{27}$

El planteamiento anterior no sugiere en modo alguno una filiación a tesis autoritarias que determinan la colocación del funcionario público en una posición de súbdito frente a la Administración Pública, partiendo del reconocimiento de la superioridad de esta como sujeto en la relación jurídica que se entable. Una concepción así se encuentra teóricamente superada y es de pacífica aceptación su inaplicabilidad actual. El funcionario público no es un mero sujeto pasivo en la relación que entabla con la Administración. El Derecho Administrativo está concebido sobre la base del equilibrio, consecuentemente, cualquier criterio que se sostenga sobre la naturaleza de la relación jurídica funcionarial debe erigirse sobre el sistema de garantías que el propio ordenamiento debe establecer para lograr dicho equilibrio, donde el Estado, a través de la ley, determina el contenido de esa relación, en correspondencia con el principio de interés público.

Si se repasan rápidamente las posturas unilateralistas y contractuales -pugna histórica- lo primero que salta a la vista es el posicionamiento de sus defensores en criterios de distinción divergentes. A priori, se ha tenido muy claro lo adjetivo, no así lo sustantivo. En tal sentido hay que cuestionarse qué es lo estatutario, qué lo contractual, qué lo unilateral o qué lo bilateral. En ocasiones, pareciese que los autores se refieren a la misma cosa cuando se explica la naturaleza de la relación funcionarial.

Sin embargo, el análisis siempre se realiza explicando la dicotomía entre la teoría estatutaria y la contractual, con énfasis en el asunto de la unilateralidad o bilateralidad del acto que determina el

${ }^{27}$ Sobre esta idea puede consultarse: DEMARTIAL (1907); HAURIOU Maurice (1927); LAUBADERE (1947); BULLRICH (1942); DIEZ (1981); BANDEIRA DE MELO (2014). 
inicio de aquella relación; lo que ha producido, más que soluciones, posturas de enfrentamiento o encasillamientos extremistas. Debe entenderse que la naturaleza de la relación jurídica en que se encuentra el funcionario frente a la Administración es una cuestión distinta de la naturaleza del acto por el cual se adquiere la condiciónde funcionario (SAYAGUÉS LASO, 1953). De tal modo, la apoyatura fundamental es la distinción entre la relación de servicio y la de empleo, pues debe tenerse claro que cuando se habla de naturaleza estatutaria se refiere exclusivamente a la relación de servicio, que es previa e independiente al vínculo de empleo.

El objeto de la primera es la atribución o declaración del status funcionarial, lo que tiene origen en un acto de voluntad del Estado, con mayor precisión en este caso, de la Administración Pública. Consecuentemente, ese acto es unilateral por su origen ya que, como todo acto administrativo, la manifestación de voluntad de la Administración Pública es válida per se. Su aceptación por parte del destinatario es requisito de eficacia, mas no de validez.

Cosa distinta es la formalización de la relación que incorpora al funcionario público que ya lo es a la organización administrativa, en un sentido estructural. Aquí es admisible cualquier mecanismo o técnica de asignación concreta al destino concebido. Puede ser un acto administrativo, que no tiene ya por objeto la creación del status, sino la determinación del vínculo estructural o puede materializarse concretamente la relación orgánica o la relación de empleo. Esta última, admite de manera muy natural un nexo consensual.

En este orden de ideas, no hay por qué negar la tesis estatutaria que no solo resulta más consecuente con la teleología de la función pública, sino que deviene más garantista para el propio funcionario público. Únicamente en su contexto es que cobra verdadera virtualidad la carrera administrativa y principios como la imparcialidad y la estabilidad. No hay libre arbitrio para la Administración Pública, ni siquiera en su carácter de empleadora, es la ley la que establece las pautas, proveyendo así coherencia, sistematicidad y seguridad jurídica a la ordenación del ejercicio de las funciones administrativas.

\section{A.3) Ordenación mediante un régimen jurídico de Derecho Administrativo}

La función pública, en tanto técnica que se concreta en la esfera de funcionamiento de la Administración Púbica, requiere un ordenamiento especial derivado de los intereses que debe satisfacer. Un marco regulatorio eficaz es imprescindible pues provee el conjunto de principios y normas jurídicas que ordenan la implementación de la institución en función de garantizar la estabilidad, consistencia, armonía y transparencia del ordenamiento jurídico. Se trata de uno de 
los sostenes principales para el establecimiento y mantenimiento de la seguridad jurídica, en pos de la coherencia del orden legal e institucional del Estado.

Por otro lado, la conceptualización adecuada del régimen jurídico del funcionario público presupone la cimentación de este sobre determinadas nociones que permitan contextualizar la figura con criterios teóricos sólidos. El vínculo singular que se establece entre el funcionario público y la Administración Pública, la axiología que la determina y la propia presencia subjetiva de ella en esa relación imprimen peculiaridades a las situaciones jurídicas que se suscitan en el ámbito de actuación del funcionario público; todo lo cual fundamenta la necesidad y existencia de una ordenación especial iusadministrativa que se sustraiga del Derecho común. Se trata de una consecuencia natural de los criterios que hasta aquí se han sostenido.

El régimen jurídico administrativo estatutario debe alcanzar las principales situaciones jurídicas derivadas de la relación de servicio.La necesidad de consagrar ese particularismo jurídico, así como la relevancia de la elaboración teórico-normativa de una noción jurídica de la categoría funcionarial que se acomode a cada contexto político y legal, es de esencial atención; sobre la base de un sistema de normas, principios y valores que garanticen tal singularidad y la capacidad de adaptación que la actualidad demanda en el contexto del fenómeno de mixtura de los sistemas de organización de la función pública.

\section{B) EL ELEMENTO SUBJETIVO}

El elemento subjetivo al que se hace referencia aquí surge de la presencia, por un lado, de la persona física que devendrá funcionario público y por otro, de la Administración Pública. Visto así, se está en presencia de una relación jurídico-administrativa que se suscita a partir de la relación de servicio. Es de ella que se desprenden las consecuencias más trascendentales para el funcionario público; en tanto relación jurídica, tiene también un elemento objetivo, constituido por el contenido del vínculo, y un elemento causal, materializado por la constitución del status funcionarial que genera la relación de servicio.

Como en toda relación jurídica, el elemento de la capacidad resulta trascendental en cuanto aptitud para ser sujeto de los derechos y obligaciones que del vínculo se desgajen. El catálogo de requisitos podrá variar según el ordenamiento jurídico dado e incluso, la configuración y alcance de alguno de ellos también pudiera resultar disímil. Sin embargo, de modo general, entre los más comunes pueden mencionarse la nacionalidad, la edad, la titulación o nivel educacional, la aptitud física y determinadas limitaciones de tipo ético o disciplinario, como la proscripción de acceso si se ha sido sancionado penal o administrativamente por ciertas conductas o si se ha impuesto alguna sanción específica. 
Referido al otro sujeto que integra la relación de servicio, la Administración Pública, debe asimilarse, a priori, en su concepción amplia. Es decir, en toda la magnitud de su aspecto estructural, incluidos todos los entes con función administrativa, principal o accesoria, que se encuentren insertos en el aparato organizacional del Estado. No obstante, es dable aclarar que se trata de una consideración general que tributa con mayor precisión en cuanto a la relación de empleo público o la relación orgánica, que implican necesariamente la inserción estructural en cualquier ente donde se localice función administrativa. A un nivel más específico, la capacidad como sujeto de la relación de servicio debe encontrar una visualidad exacta al fijarse con precisión las competencias de nombramiento en manos de los entes u órganos correspondientes.

\section{B.1)El elemento formal}

La relación de servicio tiene origen en un acto jurídico de nombramiento. Este puede traer causa en mecanismos de elección o de designación. Por la importancia del acto en cuestión y los efectos jurídicos que persigue, lo instituyen como un acto formal. Ello implica que se requiere la presencia de un instrumento que constituya la vía jurídica que permite a la Administración Pública expresar su voluntad. Las alternativas pueden ser de distinta índole, por ejemplo, una resolución, un acuerdo -si se trata de un órgano colegiado- o puede estar contenido en la propia técnica que se utilice para materializar la relación de empleo público o la orgánica. ${ }^{28}$

La forma, entonces, deviene también un elemento esencial para la constitución de la relación funcionarial. Por medio de ella, la Administración Pública manifiesta su voluntad de cara a la selección de su personal, que tiene, además, una esencia procedimental. Por tanto, al incardinarse el procedimiento administrativo correspondiente la Administración Pública debe observar formalidades concretas -oposición, concurso, provisión u oferta de puestos de trabajo, por ejemplo-. Todo lo anterior ofrece cauce a la conformación de la relación funcionarial o relación de servicio.

Concluyendo, puede recapitularse, brevemente, que ante la diversidad y disparidad de elementos que se han esgrimido en el proceso de configuración teórica de la noción de funcionario público desde su origen como categoría de interés jurídico, es preciso, en pos de su asentamiento teórico más definitivo, una perspectiva de mayor integralidad que permita una construcción

\footnotetext{
${ }^{28}$ Este último caso suele ocurrir en aquellos modelos más próximos al sistema abierto, donde los límites temporales de la relación de servicio, de empleo y orgánica, tienden a difuminarse o a coincidir. Sin embargo, aun cuanto esto suceda, es perfectamente distinguible el ámbito teórico del práctico, así como los efectos jurídicos de cada una de aquellas relaciones. Aun en estos supuestos, siempre existirá una voluntad administrativa previa en el contexto del procedimiento de selección que haga visible la expresión de la voluntad de la Administración Pública en cuanto al status funcionarial, sin el cual no puede haber determinación de destino (relación de empleo y relación orgánica).
} 


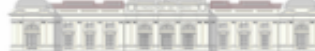

gnoseológica de la categoría con vocación técnica de universalidad y útil a efectos de su concreción en las diferentes realidades nacionales.

Debe propugnarse, pues, una visión técnica en virtud de la cual la noción jurídica de funcionario público se articule teóricamente a partir de la presencia de un elemento objetivo -que permita delimitar el ámbito administrativo como su esfera concreta de actuación, identificar el vínculo estatutario como determinante de la condición funcionarial y orientar su ordenación mediante un régimen iuspúblico-; un elemento subjetivo -que posibilite determinar la naturaleza administrativa de la relación de servicio-y un elemento formal -que precise los mecanismos de formalización del vínculo con la organización administrativa-.

\section{REFERÊNCIAS}

ALESSI, Renato. Instituciones de Derecho Administrativo.Traducción Buenaventura Pellisé Prats. Barcelona:Bosch, Casa Editorial, 1970. t. 2.

BALDINI PAPINI, Ubaldo.Il rapporto d'impiego pubblico. Italia:CEDAM Padova, 1942.

Mello, Celso AntonioBandeira de. Curso de Direito Administrativo. 31.ed. São Paulo: MalheirosEditores, 2014.

BARRA, Rodolfo. Tratado de Derecho Administrativo. Buenos Aires: EditoraÁbaco, Argentina: 2003. t. 2.

BAtTINI, Stefano. Diritto Administrativo.Milano: Giuffre Editore, 2003. t. 1.

BeRTHELEMY, Henry.Traité élémentaire deDroit Administratif. 7. ed. Paris: Arthur Rousseau Editeur, 1913.

BIELsA, Rafael. Derecho Administrativo. 3.ed. Buenos Aires: Roque Depalma, 1938. t. 2.

BIELSA, Rafael. La función pública. Argentina: Ed. Buenos Aires, 1966.

Boccardo, Gerolamo. Diritto Amministrativo. Torino:Tipografía Scolastica, 1863.

Bonnard, Roger.Précis de Droit Administratif. 4. ed. Paris: L. G. D. J, 1943.

Bullrich, Rodolfo. Principios Generales de Derecho Administrativo. Buenos Aires:

Guillermo KraftEditor, 1942. 
CABral, Pablo O.; Schreginger,Marcelo J. El régimen de empleo público en la Provincia de Buenos Aires. Buenos Aires: Abeledo-Perrot, 2009.

CASSESE, Sabino. Las bases del Derecho Administrativo. 1. ed. Traducción Luis Ortega. Madrid: Instituto Nacional de Administración Pública, 1994.

CavalcanteFilho, Joao Trindade. Regime jurídico dos servidores públicos federais. 2. ed. Salvador: Juspodivm, 2010.

CretellaJunior, José.Tratado de Direito Administrativo.O pessonal da administraçao pública.Rio de Janeiro/São Paulo: Editora Forense, 1967. v. 4.

D'Alessio, Francesco. Intituzioni di dirito amministrativo. 4. ed. Italia: Unione Tipografica-Edsitrice Torinence,1949. t. 1.

Demartial, Georges. La condition juridique du fonctionnaire. Paris:BergerLevrault et CiaÉditeurs, 1907.

DiEz, Manuel María.Manual de Derecho Administrativo. 2. ed. Buenos Aires, Argentina: Editora Plus Ultra,1981. t. 2.

DiEZ-QuiJADA, Ángel Marín.La remuneración de los funcionarios públicos.Revista Española de Derecho Administrativo,Madrid,n. 39,1962.

Duguit, León. Traité de Droit constitutionnel. 2. ed. Paris:Ancienne Librarie Fontemoing \& Cie Éditeurs,1828. t. 2.

Entrena Cuesta, Rafael. Consideraciones sobre la teoría de los contratos de la Administración. Revista de Administración Pública, Madrid, año 8, n. 24, p. 39-74, sep./dic. 1957.

Fernández VÁzQuez, Emilio. Diccionario de Derecho Público. Buenos Aires: Ediciones Astrea-Depalma, 1981.

FraGA, Gabino.Derecho Administrativo. 40. ed. Fraga, México: Editorial Porrúa, 2000.

Franco Sobrinho, Manoel de Oliveira.O principio constitucional da Moralidade Administrativa. Curitiba: CENESIS Editora, 1993.

Gallego Anarbitarte, Alfredo. Conceptos y principios fundamentales del derecho de Organización. Madrid, España:Marcial Pons, 2000.

García-TrevijanoFos, José A. Tratado de Derecho Administrativo. Revista de Derecho Privado, Madrid, 1970. v. 1.t. 2.

Gascón y Marin, José.Tratado de Derecho Administrativo. Principios y legislación Española. 7. ed. Madrid, España: C. Bermejo impresor, 1941. t. 1.

GIANNINI, Massimo Severo.Derecho Administrativo. 1. ed. Traducción de Luis Ortega. Madrid: MAP, 1991. v. 1. 
GIRIODI, L. M.Il pubblici ufficio e la gerarchia amministrativa. In:PRIMO tratato completo dei dirritto amministrativo italiano. Milano: Ed. Societá Editrice Libraria, 1900. v. 1.

Gómez De la SeRna, D. Pedro. Instituciones de Derecho Administrativo español.

Madrid: Imprenta de D. Vicente de Zalama, 1843. t. 1.

Guaita Martorell, Aurelio. Funcionario público. In: NUEVA Enciclopedia Jurídica Seix. Madrid: Francisco Seix Editor, 1960. t. x.

Hauriou, Maurice. Précis de Droit Administratif et de Droit Public.11. ed.

Paris: Société Anonyme du Recueil Sirey, 1927.

JellineK, G.Sistema dei Diritti Pubblici subbiettivi. Traducida por Gaetano Vitagliano. Milano: Ed. Libraria, 1912.

JeLLineK, G.Teoría General del Estado. Traducción Fernando de los Ríos Urruti.

Madrid: Librería General de Victoriano Suárez, 1914. t. 1.

Jeze Gastón.Les Principes généraux du droit administrati.3. ed. Paris: Giard, Francia, 1925-1930. v. 3.

KAFTANI, Chaterine.La formation du concept de fonction publique en France. Paris:Bibliothèque de Droit Public 1998. t. 196.

KAMMERER, A. La fonction publique d'après la législation allemande. Paris: Arthur Rousseau Éditeur, 1898.

Laband, Paul. Le Droit Public del Empire Allemand. Traducción de C. Gandilhon et de Th. Lacuire. Paris: V. Giard \& E. Briére Libraires-Éditeurs, 1901. t. 2.

LAFFERRIERE, E.Traité de la juridiction administrative et des recours contentieux. 2. ed. Paris,1896. t. 2.

LARES MARTíneZ, Eloy.Manual de Derecho Administrativo. 11. ed. Caracas: Universidad Central de Venezuela, 1998.

LAUBAdere, André. Manuel de droit administratif. 2. ed. Paris : L.G.D.J., 1947.

LÓPEz Oliva, Miguel Alejandro.Responsabilidad Administrativa de los servidores públicos México:UNAM, 2013.

Macarel, A. M.Cours de Droit Administratif. Paris: Gustave Thorel Libraire, 1844. t.1.p. 1 .

MACARel, A. M.Élémens de Droit Politique. Bélgica:Libraire de jurisprudence de H. Tarlier, 1934.

ManNA, Gio.Diritto Amministrativo. 2. ed. Napoli: Estabilimento Tipografico del CAV Caetano Nobile, 1860.

Marienhoff, Miguel S. Tratado de Derecho Administrativo. 3. ed. Buenos Aires: Ed. 
Abeledo-Perrot, 1965. t. 1.

MartínezBravo, Juan Alberto. Derecho Administrativo boliviano. Bolivia, 2010.

MaYer, Otto. Derecho Administrativo Alemán. 2. ed. Traducción Horacio H. Heredia y Ernesto Krotoschin.Buenos Aires, 1982. t. 4.

NeZARD, Henry.Éléments de Droit Public, Principes du Droit Public, Droit Constitutionnelle et Droit Administrati. 3. ed. Paris: Rousseau et Cie, 1922.

NeZARD, Henry.Théorie juridique de la Fonction publique. Paris: Editorial Librairie de la Société du recueil général des lois et des arrêts, 1901.

NuñEz Borjas, Humberto.Breve tratado de Derecho Administrativo del Perú. 3. ed. Arequipa, 1971. Parte 1.

Olivan, Alejandro.De la Administración Pública con relación a España. 9. ed.Madrid, España, 1843.

Orlando, V. E.Principii di Diritto Constituzionale. Firenze: G. Barbéra Editore, 1889.

Palomar Olmeda, Alberto.Derecho de la Función Pública. 4. ed. España: Dykinson, Barcelona, 1997.

PAReja, Carlos H.Curso de Derecho Administrativo teórico y práctico. 2.ed.

Bogotá: El Escolar, 1939.

PÉREZ BotIJA, Eugenio. El problema de los no funcionarios en las entidades públicas. In: AA.VV, ESTUDIOS dedicados al profesor Gascón y Marín en el cincuentenario de su Docencias. Madrid: Instituto de Estudios de la Administración Local, 1952.

Petrozziello, Modestino. Il rapporto de pubblico impiego. In: Orlando, V. E. Primo tratato completo dei dirritto amministrativo italiano. Milano: Ed. Societá Editrice Libraria Italia: 1900. v. 2. Parte 3.

PlanteY, Alain. Traité practique de la fonction publique. 3. ed. Paris : L.G.D.J, 1971.

PosadA, Adolfo.Tratado de Derecho Administrativo según las teorías filosóficas y la legislación positiva. Madrid: Librería de Victoriano Suárez,1897. t. 1.

RODRÍGUEZ ARANA, Jaime.La dimensión ética de la función pública. España: Instituto Nacional de Administración Pública, 2013.

RoDRÍGUEz R., Librado. Derecho Administrativo general y colombiano. 20. ed. Bogotá: Temis, 2017. t. 1.

Rolland, Louis.Précis de Droit Administratif. 9. ed. Paris: Librairie Dalloz, 1947.

Rondón DE SANSO, Hidelgard.El sistema Contencioso-Administrativo de la Carrera Administrativa. Caracas: Ediciones Magón, 1974. 
RousSEAU, Jean-Jacques. El Contrato social. Barcelona: Imprenta Herederos de Roca, 1836.

Royo Villanova, Segismundo. El concepto de funcionario y la relación de función pública en el nuevo derecho español. Revista de Administración Pública,Madrid, n. 44, p. 9-23, 1964.

Royo-Villanova, Antonio.Elementos de Derecho Administrativo. 20. ed. Valladolid, España:Librería Santarén, 1948. t. 1.

RuIz y Gómez, Julián M. Principios Generales de Derecho Administrativo. El personal de la Administración Pública. Exposición Doctrinal y de Derecho Positivo y Jurisprudencia Cubana. La Habana: Cultural S.A, 1935.

SANDulli, Aldo M. Manuale di Diritto Amministrativo.15. ed. Nápoles: Jovene Editore, 1989. t. 1.

Santi Romano.Principii di Diritto Amministrativo italiano. 2. ed. Milano: Societá Editrice Libraria, 1906.

SARALEGUi y MedINA, Leandro. Nociones Generales de Administración, de Derecho Administrativo y de Economía política. Madrid: Establecimiento tipográfico de Estrada, 1865.

SAyaguÉs Laso, Enrique.Tratado de Derecho Administrativo. Montevideo, 1953. T. 1.

SCOLARI, SAVEIRo.Del Diritto Amministrativo. Pisa: Fratelli editori, 1866.

VIDAL PeRdomo, Jaime. Derecho Administrativo. Bogotá: Legis, 2005.

VillegasBasavilbaso, Benjamín. Tratado de Derecho Administrativo. Buenos Aires: Ed. TEA, 1951.t. 3.

VITTA, Cino.Diritto Amministrativo. 4. ed. Torino: Unione TipograficoEditice Torinece, 1954. v. 1.

VIVIEN, M.Études administrative. 1. ed. Paris: Guillaumin Libraire Francia, 1845.

WALINE, Marcel.Manuel élémentaire de droit administratif. 9. ed. Paris : Librairie de Recueil Sirey, 1963.

WeLteR, Henri.Le contrôle juridictionnel de la Moralité administrative. Paris: Librairie Recueil Sirey Francia, 1929.

Younes Moreno, Diego. Curso de Derecho Administrativo. 10. ed. Bogotá: Temis, 2016.

ZanobInI, Guido.Corso di Diritti Amministrativo. Milano: Dott. A. Giuffé-Editore,1950. t. 3 . 